$03,09,12$

\title{
Рекомбинация и спиновая динамика экситонов в непрямозонных квантовых ямах и квантовых точках
}

\section{(C) T.C. Шамирзаев}

Институт фозики полупроводников им. А.В. Ржанова СО РАН, Новосибирск, Россия

Уральский федеральный университет им. Б.Н. Ельцина,

Екатеринбург, Россия

E-mail: tim@isp.nsc.ru

Рассматривается поведение экситонов в гетероструктурах с непрямозонными квантовыми ямами $\mathrm{GaAs} / \mathrm{Al} \mathrm{As}$ и квантовыми точками (In, Al)As/AlAs. Продемонстрированы возможности: управляемого изменения времени излучательной рекомбинации экситона в диапазоне от нескольких десятков наносекунд до десятков микросекунд; экспериментального исследования спиновой динамики долгоживущих локализованных экситонов; использования резонансных оптических методов для возбуждения непрямозонных экситонных состояний.

Работа выполнена при финансовой поддержке правительства Российской Федерации, постановление № 211, контракт № 02.A03.21.0006, РФФИ проект № 16-02-00242 и Deutsche Forschungsgemeinschaft and the Russian Foundation for Basic Research via ICRC TRR160, ФАНО РФ проект № AAAA-A17-117042110141-5.

DOI: $10.21883 /$ FTT.2018.08.46240.08Gr

\section{1. Введение}

Экситоны во многом определяют оптические свойства низкоразмерных полупроводниковых гетероструктур, поэтому их изучение интересно, как с точки зрения фундаментальной физики, так и для приборных применений [1]. Одним из фундаментальных параметров низкоразмерных экситонов является время их жизни, которое в значительной мере зависит от энергетического спектра гетероструктуры. Энергетическое строение низкоразмерных структур определяет распределение носителей заряда: (1) В пространстве квазиимпульсов, где может реализоваться два варианта (i) прямозонные структуры, когда электрон и дырка расположены в одной и той же точке зоны Бриллюэна и (ii) непрямозонные структуры, образующиеся, когда носители заряда имеют разное значение квазиимпульса; (2) В реальном пространстве, где также возможно два варианта (iii) структуры первого рода, в которых оба носителя заряда (и электрон, и дырка) локализованы в одном из составляющих структуру полупроводников и (iv) структуры второго рода, в которых электроны и дырки разделяются в реальном пространстве между слоями различных полупроводников. Таким образом, в общем случае существуют четыре различных типа энергетического спектра низкоразмерных гетероструктур, показанных на рис. 1.

В хорошо изученных прямозонных полупроводниковых квантовых ямах (КЯ) и квантовых точках (KT) (рис. 1,c), таких как (In,Ga)As/GaAs или $\mathrm{GaAs} /(\mathrm{Al}, \mathrm{Ga}) \mathrm{As}$, характерные времена рекомбинации экситона лежат в наносекундном диапазоне [2]. Пространственное разделение носителей заряда в прямозонных гетероструктурах второго рода, например в $\mathrm{GaSb} / \mathrm{GaAs}$ КЯ (рис. 1,e), позволяет увеличить времена жизни экситона до сотен наносекунд [3]. С другой стороны, закон сохранения квазиимпульса накладывает ограничения на рекомбинацию экситонов в непрямозонных гетероструктурах первого рода, таких как (In, Al)As/AlAs $($ рис. $1, d)$, увеличивая времена рекомбинации экситона до сотен микросекунд [4]. Дополнительного увеличения времени жизни можно достигнуть в непрямозонных гетерструктурах второго года, например в GaAs/AlAs КЯ и сверхрешетках (рис. $1, f$ ), при одновременном разделении носителей заряда, как в реальном пространстве, так и в пространстве квазиимпульсов [5].

Полупроводниковые гетероструктуры с непрямой запрещенной зоной являются удобными объектами для анализа физических процессов, изучение которых затруднено в прямозонных структурах. Характерным примером такого процесса является спиновая динамика локализованных экситонов. Локализация, как это было показано в многочисленных теоретических работах, приводит к подавлению механизмов, определяющих переворот спина свободно двигающихся электронных возбуждений, таких как механизмы Эллиота-Яфета и Дьяконова-Переля, а время жизни спиновых состояний локализованных экситонов, может достигать миллисекунд [6,7]. Поэтому для экспериментального изучения спиновой динамики локализованных экситонов требуются гетероструктуры, в которых времена жизни экситонов сравнимы со временами их спиновой релаксации.

В настоящей статье рассматриваются процессы некогерентной динамики рекомбинации, комбинационного рассеяния с переворотом спина и спиновой динамики экситонов в непрямозонных квантовых ямах и квантовых точках. Отметим, что если непрямозонные гетероструктуры второго рода изучаются вот уже более 30 лет, главным образом, благодаря работам, посвященным иссле- 


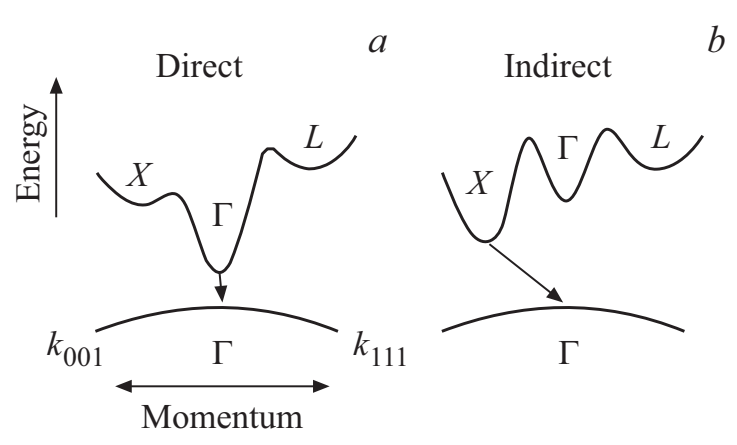

Heterostructures of type I

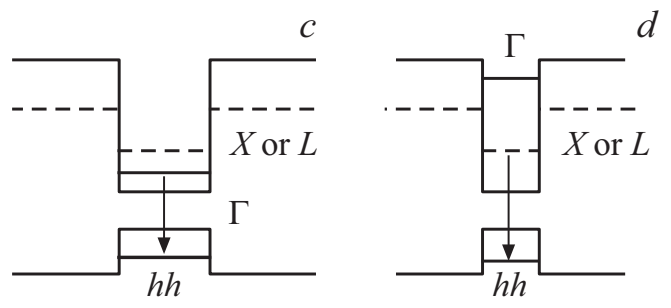

Heterostructures of type II

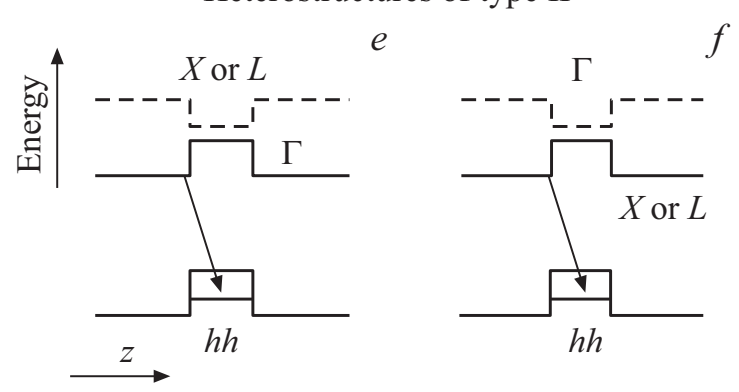

Рис. 1. Зонные диаграммы гетероструктур [19]. В пространстве квазиимпульсов: $(a)$ прямозонные и $(b)$ непрямозонные. В реальном пространстве: (c) прямозонные первого рода, $(d)$ непрямозонные первого рода, (e) прямозонные второго рода, $(f)$ непрямозонные второго рода. Стрелками обозначены оптические переходы экситонов в основное состояние.

дованию KT $\mathrm{Ge} / \mathrm{Si}[8]$ и короткопериодных сверхрешеток GaAs/AlAs [9], то изучение непрямозонных гетероструктур первого рода началось относительно недавно. Тем не менее, несмотря на то, что первые сообщение об этих объектах появились около десяти лет назад, за прошедшее время было показано, что КЯ и КТ с таким энергетическим спектром широко распространены $[10,11]$ и могут быть реализованы на основе бинарных соединений $\mathrm{A}_{3} \mathrm{~B}_{5}$ : арсенидов, фосфидов и антимонидов с кубической симметрией элементарной ячейки таких как, например: InAs/AlAs [12], GaSb/AlAs [13,14], InSb/AlAs [14], $\mathrm{GaAs} / \mathrm{GaP}$ [15,16], GaSb/GaP [17], (In,Ga)As/GaP [18]. Для демонстрации особенностей рекомбинации и спиновой динамики непрямых в пространстве квазиимпульсов экситонов в статье приведены результаты исследования двух модельных систем: ансамбля квантовых точек (In, Al)As/AlAs первого рода [12] и ультратонкой квантовой ямы GaAs/AlAs второго рода $[19,20]$.
Статья организована следующим образом: некогерентная динамика рекомбинации экситонов и метод управления временем их жизни в непрямозонных квантовых точках описаны во втором разделе. В разделе 3 рассматривается спиновая динамика локализованных отрицательно заряженных и нейтральных экситонов в сильных магнитных полях. Резонансные методы возбуждения непрямозонных экситонных состояний, такие как резонансное комбинационное рассеяние света с переворотом спина (РКРС) и оптическая ориентация описаны в разделе 4.

\section{2. Некогерентная динамика рекомбинации экситонов в непрямозонных гетероструктурах}

Квазиимпульс экситона, составленного из принадлежащего боковой долине зоны проводимости электрона и дырки, находящейся в центре зоны Бриллюэна, существенно больше, чем импульс фотона с такой же энергией, поэтому закон сохранения импульса накладывает ограничения на излучательную рекомбинацию таких экситонов. Основными механизмами излучательной рекомбинации экситонов в непрямозонных гетероструктурах являются (i) одновременное испускание фотона и фонона или (ii) смешивание электронных состояний различных долин зоны проводимости на гетерогранице, ответственное за появление в спектрах ФЛ линий бесфонной рекомбинации. В непрямозонных КТ первого рода основным каналом излучательных переходов экситонов является бесфононая рекомбинация [12]. Следовательно, вероятность рекомбинации экситона в таких КТ определяется структурой гетерограницы КТ/матрица, которая и определяет динамику их рекомбинации.

В данном разделе показано влияние структуры гетерограницы КТ/матрица на динамику рекомбинации и распределение времен жизни экситонов в ансамблях непрямозонных KT (In, Al)As/AlAs первого рода (энергетический спектр приведен на рис. $1, d)$. Изучаемые структуры содержали один слой (In, Al)As квантовых точек, помещенный между слоями AlAs толщиной $50 \mathrm{~nm}$. Подробности формирования гетероструктур описаны в работах $[12,21]$. Низкотемпературный спектр ФЛ структуры с (In, Al)As/AlAs KT, показан на рис. 2, a (кривая 1). Спектр структур содержит полосу WL, обусловленную рекомбинацией экситонов в смачивающем слое и полосы DQD и IQD, связанные, соответственно, с рекомбинацией экситонов в подансамблях прямозонных и непрямозонных КТ [22].

Характерный диаметр, плотность и состав твердого раствора КТ, сформированные в различных матрицах в процессе самоорганизации по механизму Странского-Крастанова, определяются главным образом, температурой эпитаксии и временем формирования КТ. Несмотря на перемешивание материалов КТ и матрицы, имеющее место в процессе эпитаксиального роста, 

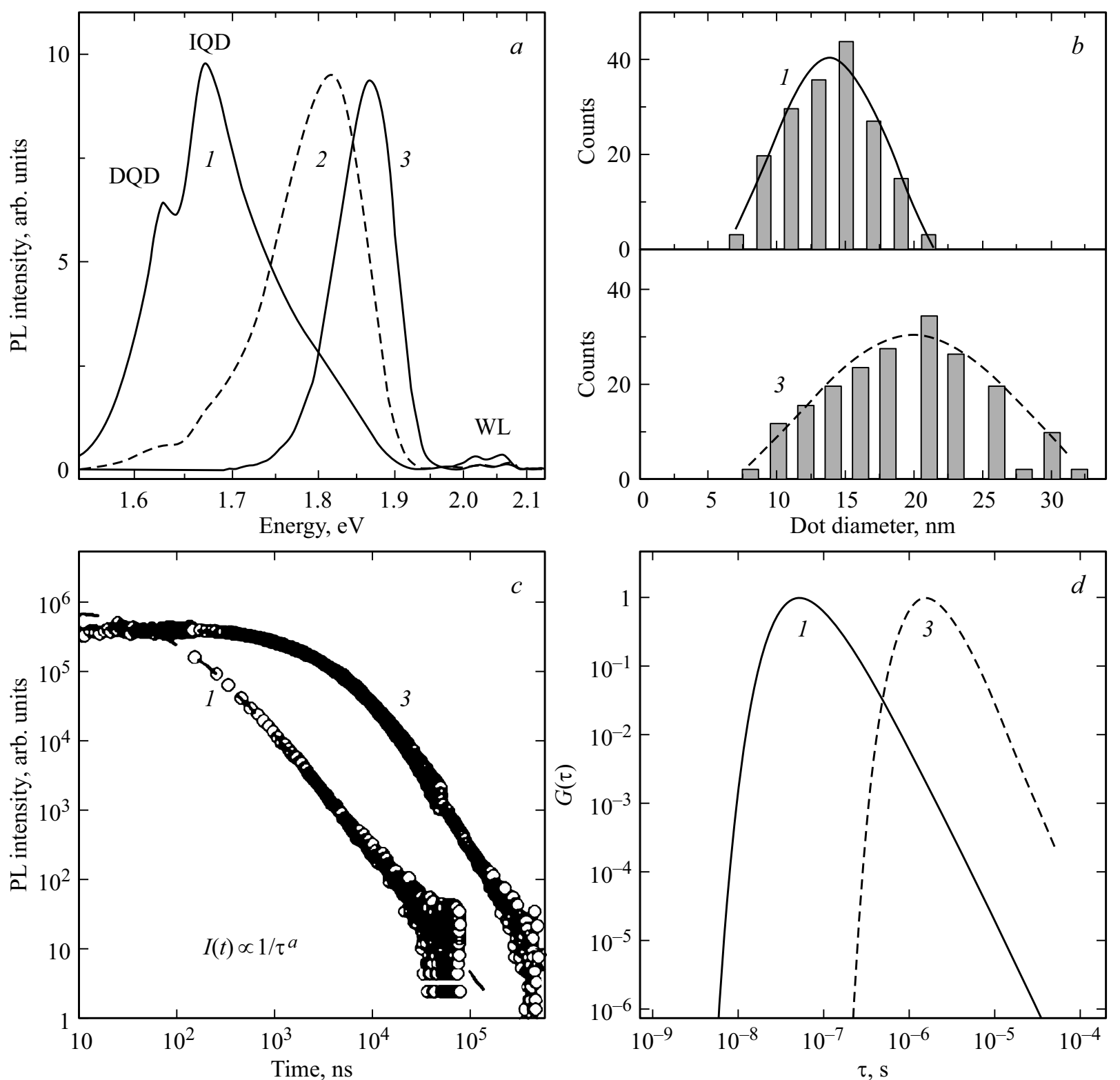

Рис. 2. Низкотемпературные (5К) спектры ФЛ-структур с КТ, отожженных в течении одной минуты в потоке водорода при температурах: $1-$ неотожженная, $2-700^{\circ} \mathrm{C}, 3-850^{\circ} \mathrm{C}$. Группа полос WL, обусловлена рекомбинацией в смачивающем слое; (b) Гистограммы распределения диаметров КТ в структурах до (1) и после (3) отжига при температуре $850^{\circ} \mathrm{C}$; $(c)$ Динамика экситонной ФЛ (кружочки) в КТ, измеренные при температуре $T=5 \mathrm{~K}$ в максимуме полосы IQD до $(1)$ и после $(3)$ отжига при температуре $850^{\circ} \mathrm{C}$. Штриховыми линиями отмечены кинетические кривые, рассчитанные с использованием функции распределения $G(\tau)$ определяемой выражением (2) с параметрами, приведенными в тексте; $(d)$ Нормированные распределения $G(\tau)$ в ансамбле КТ до (1) и после (3) отжига при температуре $850^{\circ} \mathrm{C}$.

самоорганизованные КТ имеют резкую гетерограницу КТ/матрица [23,24]. Это связано с тем, что состав КТ определяется перемешиванием в процессе переноса материала вдоль смачивающего слоя при их формировании [25-27]. В то время как поверхность КТ любого состава, формируется в виде кристаллографических плоскостей, обеспечивающих минимальную энергию интерфейса. Эта поверхность остается устойчивой к перемешиванию в процессе заращивания КТ. Изменить атомную структуру гетерограницы КТ/матрица можно при послеростовом высокотемпературном отжиге, за счет диффузии материала из которого состоит КТ в окружающую матрицу.

Отжиг структуры с КТ при высоких температурах $\left(T_{a n}\right)$ сопровождается, как это видно на рис. 2, $a$, сдвигом полосы IQD в высокоэнергетическую область спектра, причем величина сдвига возрастает с повышением $T_{a n}$. Энергия оптического перехода при рекомбинации экситонов в КТ определяется двумя основными факторами: энергией размерного квантования носителей заряда, 
которая уменьшается с возрастанием размера КТ и шириной запрещенной зоны составляющего КТ твердого раствора InAlAs, которая возрастает с уменьшением доли InAs.

Для того чтобы оценить влияние отжига на размер КТ проводились измерения планарных изображений неотожженной и отожженной при $T_{a n}=850^{\circ} \mathrm{C}$ структур в просвечивающем электронном микроскопе. Построенные по этим изображениям гистограммы распределения диаметров КТ показаны на рис. 2, b. Отжиг приводит к возрастанию среднего размера с 13.8 до $19.6 \mathrm{~nm}$. Возрастание размера КТ после отжига, происходит в результате диффузии InAs от КТ в окружающую матрицу AlAs. Следовательно, отжиг КТ приводит к образованию размытого слоя твердого раствора $\mathrm{In}_{x} \mathrm{Al}_{1-x}$ As переменного состава (от InAlAs соответствующего составу КТ, до чистого AlAs) на гетерогранице КТ/матрица. Толщина этого слоя определяется температурой и длительностью отжига. Таким образом, высокоэнергетический сдвиг, имеющий место при отжиге структуры, обусловлен возрастанием ширины запрещенной зоны InAlAs при уменьшении InAs в составе КТ. Это возрастание превосходит уменьшение энергии размерного квантования, связанного с увеличением размера КТ в отожженной структуре.

Динамика рекомбинации экситонов в ансамбле КТ после импульсного возбуждения, показанная на рис. 2, для гетероструктур до и после отжига, содержит два характерных участка: участок относительно слабого затухания ФЛ непосредственно после импульса возбуждения, сменяющийся затуханием, описываемым степенным законом $I(t) \sim(1 / t)^{\alpha}$. Неэкспоненциальность динамики экситонной ФЛ в ансамблях КТ обусловлена вкладом экситонов, излучающих на одной длине волны, но локализованных в КТ с разными временами излучательной рекомбинации $\tau$ и может быть описана выражением

$$
I(t)=\int_{0}^{\infty} G(t) e^{-\frac{t}{\tau}} d \tau .
$$

определенная в работе [21] функция распределения времен жизни экситонов

$$
G(\tau)=\left(C / \tau^{\gamma}\right) e^{-\frac{\tau_{0}}{\tau}},
$$

где $C-$ константа, $\gamma=\alpha+1$ (где $\alpha$ наклон кривой затухания), а $\tau_{0}$ характеризует наиболее вероятное время жизни экситонов в ансамбле КТ, позволяет описывать динамику рекомбинации экситонов в широком динамическом диапазоне.

Параметры функции распределения зависят от условий отжига, как это показано на рис. 2, $d$ и равны $\left(\gamma=2.55, \tau_{0}=0.13 \mu \mathrm{s}\right)$ и $\left(\gamma=3.40, \tau_{0}=5.2 \mu \mathrm{s}\right)$, для соответственно неотожженной и отожженной при температуре $850^{\circ} \mathrm{C}$ гетероструктур [21]. Т. е. отжиг приводит к существенному увеличению характерного времени жизни экситонов в ансамбле КТ, которое может из- меняться, как это показано в работе [21], от десятков наносекунд до почти десяти микросекунд.

Проведенный в работе [21] анализ влияния на время жизни экситона размера КТ и „размытости“ гетерограницы КТ/матрица показывает, что возрастание времени жизни непрямого в пространстве квазиимпульсов экситона в КТ определяется, главным образом, расплыванием гетерограницы КТ/матрица в процессе отжига. Проведенные в той же работе оценочные расчеты, позволяют получить аналитическую зависимость, качественно показывающую влияние размера КТ и „размытости“ гетерограницы КТ/матрица на время жизни непрямого в пространстве квазиимпульсов экситона. В соответствии с этими расчетами время жизни экситона, рассеивающего квазиимпульс на гетерогранице, $\tau \sim \exp (d / a+d / L)$, здесь $a$ - постоянная решетки, $L-$ высота КТ, и $d-$ толщина слоя твердого раствора (In, Al)As на гетерогранице КТ/матрица. Время жизни экситона определяется первым членом в экспоненте, поскольку отношение $d / a$ всегда $>1$ и возрастает с увеличением толщины „размытого“ слоя на гетерогранице, тогда как отношение $d / L$ всегда $<1$. Таким образом, увеличивая толщину слоя $d$ посредством высокотемпературного отжига гетероструктур с КТ можно управляемо увеличивать время жизни экситонов. Необходимо, однако, отметить, что повышение времени жизни экситона с возрастанием отношения $d / a$ имеет свой предел. Как только вероятность испускания фонона станет больше, чем вероятность рассеяния квазиимпульса за счет смешивания электронных состояний на гетерогранице, механизм излучательной рекомбинации экситона изменится, и выполнение закона сохранения квазиимпульса будет осуществляться за счет испускания фононов. В гетеросистеме (In, Al)As/AlAs ограниченное испусканием фононов время жизни экситона, имеет значение больше сотни микросекунд [4].

\section{3. Спиновая динамика экситонов в непрямозонных гетероструктурах в магнитном поле}

Для изучения спиновой динамики спиновую систему, как правило [28], необходимо вывести из равновесия и создать неравновесную заселенность спиновых состояний. Неоднородность населенности можно создавать с помощью оптической накачки - возбуждением циркулярно поляризованным светом, однако, слабое экситонфотонное взаимодействие создает проблемы для использования этой методики в непрямозонных гетероструктурах. Удобной альтернативой является создание неравновесной спиновой заселенности расщепленных магнитным полем состояний экситонов при нерезонансном возбуждении неполяризованным или линейно поляризованным светом. Такое возбуждение не привносит угловой момент в электронную подсистему и, следовательно, в начальный момент времени после возбуждения расщепленные полем состояния заселяются одинаково. 

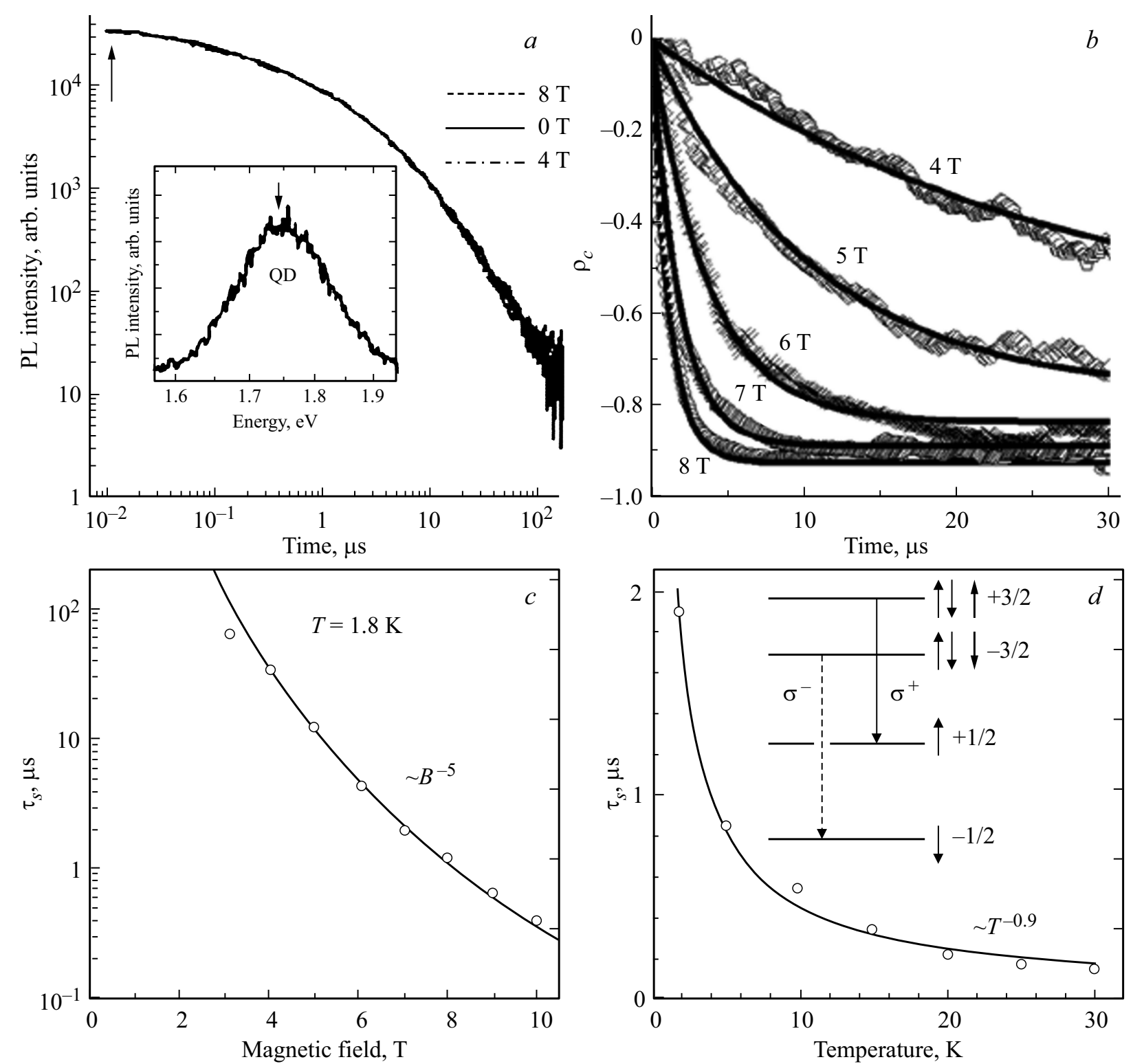

Рис. 3. (а) Динамика неполяризованной экситонной ФЛ легированных (In, Al)As/AlAs КТ при температуре $1.8 \mathrm{~K}$ в продольных магнитных полях 0, 4 и 8T [29]. Стрелкой обозначен момент окончания импульса лазерного излучения. Данные приведены в двойном логарифмическом масштабе, удобном для представления неэкспоненциальных кривых. Спектр ФЛ структуры приведен, на вставке. Стрелкой обозначена энергия, на которой проводились измерения динамики ФЛ. (b) Динамика степени циркулярной поляризации ФЛ в максимуме полосы QD $(1.72 \mathrm{eV})$ в продольных магнитных полях при $T=1.8 \mathrm{~K}$. Сплошными линиями показаны кривые, рассчитанные по формуле (5) с различными подгоночными параметрами $\tau_{S}$. Зависимости времени спиновой релаксации отрицательно заряженного экситона от $(c)$ магнитного поля и $(d)$ температуры. Открытыми кружками показаны данные, определенные посредством аппроксимации экспериментальных данных формулой (5). Сплошными линиями показаны результаты описания $\tau_{S}(B)$ и $\tau_{S}(B)$ степенными функциями. На вставке показана последовательность энергетических уровней начального и конечного состояний с различными проекциями спина электрона (тонкие стрелки) и дырки (толстые стрелки).

При больших (по сравнению с термической энергией $k T$ ) величинах зеемановского расщепления одинаковая заселенность экситонных состояний с различными проекциями спина (и соответственно различными энергиями) соответствует термодинамически неравновесному распределению. С течением времени процессы, изменяющие энергию и проекцию спина экситона (процессы спиновой релаксации), стремятся привести заселенности экситонных состояний в соответствие с равновесным (больцмановским) распределением.

В этом разделе приводится описание спиновой динамики отрицательно заряженных и нейтральных экситонов, локализованных соответственно, в непрямозонных (In, Al)As/AlAs квантовых точках и GaAs/AlAs квантовой яме. Эксперименты проводились в геометрии Фарадея и с отклонением вектора напряженности магнитного 
поля от оси роста структур до 90 градусов (геометрия Фохта) в магнитных полях $B=0-10$ Т при температурах $1.8-30 \mathrm{~K}$. Фотолюминесценция возбуждалась импульсами третьей гармоники YAG лазера $(\hbar \omega=3.49 \mathrm{eV})$ длительностью $5 \mathrm{~ns}$ и регистрировалась матрицей кремниевых фотоприемников, на основе прибора с зарядовой связью (ПЗС).

\section{А. Отрицательно заряженные экситоны в} (In, Al)As/AlAs квантовых точках. Изучаемая структура содержала десять слоев (In, Al)As квантовых точек первого рода (энергетический спектр приведен рис. $1, d$ ), с плотностью $5 \cdot 10^{10} \mathrm{~cm}^{2}$ помещенных между слоями AlAs толщиной $50 \mathrm{~nm}$. Для того чтобы заполнить ансамбль квантовых точек носителями заряда, в среднем по одному электрону на КТ, в каждом слое AlAs на глубине $2 \mathrm{~nm}$ под слоем КТ помещался дельтаслой донорной примеси с плотностью атомов кремния $1 \cdot 10^{12} \mathrm{~cm}^{2}$. Детали формирования структуры описаны в работе [29].

Спиновая динамика заряженных экситонов, помещенных в продольное магнитное поле, описывается в рамках простой модели с двумя состояниями, характеризующимися различными проекциями полного углового момента (спина) экситона и расщепляющихся на величину $\Delta E_{\uparrow \downarrow}$. Рекомбинация отрицательно заряженных экситонов проиллюстрирована на вставке к рис. 3, $d$. В начальном состоянии в КТ локализован отрицательно заряженный экситон, состоящий из двух электронов и тяжелой дырки. В конечном состоянии, после излучения фотона, в КТ остается электрон. Излучательные переходы между этими состояниями (и соответственно поляризация излучаемых фотонов) определяются правилами отбора по проекции спина.

Динамика изменения заселенности состояний может быть описана системой кинетических уравнений [29]

$$
\begin{gathered}
\frac{d n_{\uparrow}}{d t}=C_{\uparrow}-\frac{n_{\downarrow}}{\tau}-\frac{n_{\downarrow}}{\tau_{S}}+\frac{n_{\downarrow}}{\tau_{S}} \exp \left[-\frac{\Delta E_{\uparrow \downarrow}}{k_{B} T}\right], \\
\frac{d n_{\downarrow}}{d t}=C_{\downarrow}-\frac{n_{\downarrow}}{\tau}+\frac{n_{\uparrow}}{\tau_{S}}-\frac{n_{\downarrow}}{\tau_{S}} \exp \left[-\frac{\Delta E_{\uparrow \downarrow}}{k_{B} T}\right],
\end{gathered}
$$

где $C_{\uparrow}=C_{\downarrow}-$ скорости генерации, а $n_{\uparrow}$ и $n_{\downarrow}$ концентрации заряженных экситонов в верхнем и нижнем состояниях с различными проекциями спина, $\tau$ и $\tau_{S}$ время жизни и время спиновой релаксации экситона соответственно.

Интенсивность ФЛ с поляризацией $\sigma^{+/-}$пропорциональна $n_{\uparrow / \downarrow}$ поэтому, время спиновой релаксации экситона можно определить, описав экспериментально измеренную динамику степени циркулярной поляризации ФЛ $\left(\rho_{c}\right)$ выражением

$$
\rho_{c}\left(t, \tau . \tau_{S}\right)=\frac{n_{\downarrow}\left(t, \tau, \tau_{S}\right)-n_{\uparrow}\left(t, \tau, \tau_{S}\right)}{n_{\downarrow}\left(t, \tau, \tau_{S}\right)+n_{\uparrow}\left(t, \tau, \tau_{S}\right)},
$$

взяв $\tau_{S}$ в качестве подгоночного параметра. Особенностью ансамблей непрямозонных КТ является разброс параметров, приводящий к дисперсии времен жизни экситонов, излучающих на одной длине волны, но локализованных в различных КТ. Дисперсия времен жизни экситонов в ансамбле КТ описывается распределением $G(\tau)$, обсуждавшемся во втором разделе. Для учета влияния этой дисперсии квантовые точки в ансамбле можно разбить на группы так, чтобы в каждой КТ, принадлежащей одной и той же группе, время жизни экситона было одинаковым. Внутри каждой группы КТ динамика заселенности экситонов в состояниях с различными проекциями спина $n_{\uparrow}$ и $n_{\downarrow}$ описывается решением системы уравнений (3). Полное число экситонов в состояниях с различными проекциями спина $\left(N^{\uparrow / \downarrow}\right)$ в ансамбле КТ можно вычислить посредством суммирования $n_{\uparrow / \downarrow}$ по всем группам КТ с учетом $G(\tau)$ : $N^{\uparrow / \downarrow}\left(t, \tau_{S}\right)=\int G(\tau) n_{\uparrow / \downarrow}\left(t, \tau, \tau_{S}\right) d \tau$. Таким образом, динамику $\rho_{c}$ для ансамбля КТ с дисперсией времен жизни экситона можно описать выражением

$$
\rho_{c}\left(t, \tau_{S}\right)=\frac{N^{\downarrow}\left(t, \tau_{S}\right)-N^{\uparrow}\left(t, \tau_{s}\right)}{N^{\downarrow}\left(t, \tau_{S}\right)+N^{\uparrow}\left(t, \tau_{s}\right)} .
$$

Заряженному экситону в процессе перехода между состояниями с различной проекцией спина необходимо изменить энергию на величину $\Delta E_{\uparrow / \downarrow}$ и удовлетворить требованию закона сохранения проекции углового момента. Изменение энергии в процессах спиновой релаксации обеспечивается за счет взаимодействия с колебаниями решетки, как правило, посредством одного из двух процессов: испускания (поглощения) одного акустического фонона или двух-фононного рамановского процесса, заключающегося в поглощении одного фонона с одновременным испусканием другого, так чтобы разница энергий двух фононов равнялась $\Delta E_{\uparrow \downarrow}[7,30,31]$. Сохранение проекции углового момента может обеспечиваться либо за счет сверхтонкого взаимодействия экситона с ядерными спинами, либо за счет спин-орбитального взаимодействия, которое смешивает состояния с различными проекциями спина [7]. Различные механизмы, обеспечивающие переворота спина по-разному зависят от $\Delta E_{\uparrow \downarrow}$ и температуры [7,30,31] и это позволяет определить доминирующий механизм спиновой релаксации экситона анализируя полевые и температурные зависимости $\rho_{c}$ в ансамблях КТ.

Спиновая релаксация отрицательно заряженных экситонов в ансамбле (In, Al)As/AlAs KT, в продольном магнитном поле изучалась в работе [29], посредством измерения динамики наведенной магнитным полем степени циркулярной поляризации экситонной ФЛ (спектр ФЛ, измеренный при $T=1.8 \mathrm{~K}$ приведен на вставке к рис. $3, a)$. Люминесценция возбуждалась линейно поляризованным светом, не привносящим углового момента в электронную подсистему. Динамика степени циркулярной поляризации ФЛ в различных магнитных полях приведена на рис. $3, b$. ФЛ отрицательно поляризована, т.е. с течением времени после импульса возбуждения интенсивность $\sigma^{+}$поляризованной компоненты ФЛ затухает быстрее, чем интенсивность $\sigma^{-}$поляризованной 
компоненты. В магнитном поле 8 Т степень циркулярной поляризации ФЛ в течение нескольких микросекунд возрастает от 0 до насыщения, которое наступает при $P_{c}^{\text {sat }} \approx-0.92$. При уменьшении напряженности магнитного поля время нарастания степени циркулярной поляризации ФЛ увеличивается, а значение $P_{c}^{\text {sat }}$, при котором она выходит на насыщение, уменьшается. В магнитных полях с напряженностью 5 и 4 Т степень циркулярной поляризации ФЛ не успевает выйти на насыщение за время наблюдения $(30 \mu \mathrm{s})$. Повышение температуры до $30 \mathrm{~K}$ приводило к ожидаемому уменьшению $P_{c}^{\text {sat }}$, и к ускорению спиновой релаксации.

Поскольку динамика степени циркулярной поляризации как это видно из выражений (4 и 5) зависит не только от времени спиновой релаксации, но также, от $G(\tau)$, возникает вопрос о полевой и температурной зависимостях времени жизни экситона в КТ и его распределения $G(\tau)$ по ансамблю. Форма кривой затухания экситонной ФЛ (In, Al)As/AlAs KT после импульса возбуждения при $T<50 \mathrm{~K}$ практически не зависит от напряженности магнитного поля и температуры (рис. $3, a$ для $T=2 \mathrm{~K}$ ). Следовательно, в этом диапазоне полей и температур время жизни экситона в КТ и $G(\tau)$ сохраняются неизменными.

Для определения доминирующего механизма спиновой релаксации отрицательно заряженного экситона работе [29] было экспериментально определено распределение $G(\tau)$ и, с использованием выражения (5), построены полевые и температурные зависимости $\tau_{S}$. Эти зависимости хорошо описываются степенными функциями $\tau_{S}(T) \propto B^{-5}$ и $\tau_{S}(T) \propto T^{-0.9}$, как это видно на рис. $3, c$ и $d$ соответственно. Следовательно, доминирующим механизмом спиновой релаксации отрицательно заряженных экситонов в (In, Al)As/AlAs KT является спинрешеточная релаксация с участием одного акустического фонона [29].

В. Нейтральные экситоны в квантовых ямах GaAs/AlAs. В отличие от случая заряженных экситонов, спиновая динамика которых, как это продемонстрировано в предыдущем подразделе, хорошо описывается в рамках двухуровневой системы, для описания динамики спиновой релаксации нейтрального экситона необходимо использовать более сложную модель $[19,20]$. Тонкая структура экситона в КЯ GaAs/AlAs (энергетический спектр КЯ показан на рис. $1, f)$, формируется из состояний электрона со спином $1 / 2$ и тяжелой дырки с угловым моментом 3/2, с одинаковыми знаками $g$ факторов $\left(g_{e}, g_{h h}>0\right)$. Сложение моментов этих квазичастиц приводит к формированию четырех состояний, двух оптически активных, характеризующихся проекциями момента \pm 1 и двух оптически неактивных, с проекциями момента \pm 2 , рекомбинация из которых запрещена правилами отбора по спину.

Динамика изменения заселенности этих состояний в магнитном поле, приводит к весьма необычному поведению интенсивности, степени наведенной полем цирку- лярной фотолюминесценции экситонов и их динамики, не наблюдаемому в двухуровневых системах.

Низкотемператрурные $(2 \mathrm{~K})$ спектры неполяризованной ФЛ в изучаемой структуре с двумя мономолекулярными слоями GaAs, помещенными между слоями AlAs толщиной $50 \mathrm{~nm}$ в продольных магнитных полях (геометрия Фарадея) различной напряженности показаны на рис. 4, $a$. Спектры содержат полосу бесфонного перехода NP и полосы переходов с участием акустических и оптических фононов GaAs и AlAs, принадлежащих $X$ минимуму зоны Бриллюэна. Фононные повторения обусловлены испусканием поперечного акустического (ТА) фонона AlAs (с энергией $12 \mathrm{meV}$ ), продольных оптических (LO) фононов GaAs (30 meV) и AlAs (48 meV) [32]. $\mathrm{C}$ ростом напряженности магнитного поля происходит резкое уменьшение интенсивности ФЛ. Поскольку, как показано в работе [19], изменения всех параметров ФЛ и ее динамики в зависимости от напряженности и ориентации магнитного поля и температуры для всех полос ФЛ одинаково, в дальнейшем описании мы сфокусировались, без потери общности, на поведении самой интенсивной полосы в спектре - повторения с испусканием LOфонона AlAs.

Падение интенсивности сопровождается увеличением времени рекомбинации экситонов, показанным на рис. $4, b$. Изменение ориентации магнитного поля (поворот поля в геометрию Фохта, (рис. $4, c$ ) или повышение температуры (рис. $4, d$ ) приводят к восстановлению интенсивности ФЛ и уменьшению времени излучательной рекомбинации [19].

Приложение к структурам магнитного поля приводит к появлению наведенной циркулярной поляризации ФЛ. Интенсивность $\sigma^{+}$поляризованной компоненты ФЛ меньше, чем интенсивность $\sigma^{-}$поляризованной компоненты, т. е. ФЛ поляризована отрицательно [20]. Полевая зависимость степени поляризации $\rho_{c}(B)$ в геометрии Фарадея приведена на рис. 5, $a$ для различных температур. При температуре $1.8 \mathrm{~K}$ с ростом напряженности поля абсолютное значение степени наведенной циркулярной поляризации $\left|\rho_{c}\right|$ сначала возрастает, достигая значения 0.6 при $4.5 \mathrm{~T}$, а в больших полях начинает уменьшаться (до 0.4 при 10T). При повышении температуры значение напряженности поля, при котором степень поляризации ФЛ достигает своего максимального значения, монотонно смещается в область более высоких полей.

В больших магнитных полях при отклонении поля от геометрии Фарадея абсолютное значение степени наведенной полем циркулярной поляризации монотонно возрастает, как это видно на рис. 5, с и выходит на насыщение $(0.72$ при $10 \mathrm{~T})$ в области углов отклонения 30-60 градусов. Температурная зависимость абсолютного значения степени наведенной магнитным полем $10 \mathrm{~T}$ поляризации $\left|\rho_{c}\right|$, приведенная на рис. 5, $b$ немонотонна. Она увеличивается от 0.4 до 0.6 с ростом температуры от 2 до $4 \mathrm{~K}$ и начинает монотонно уменьшаться при более высоких температурах. 

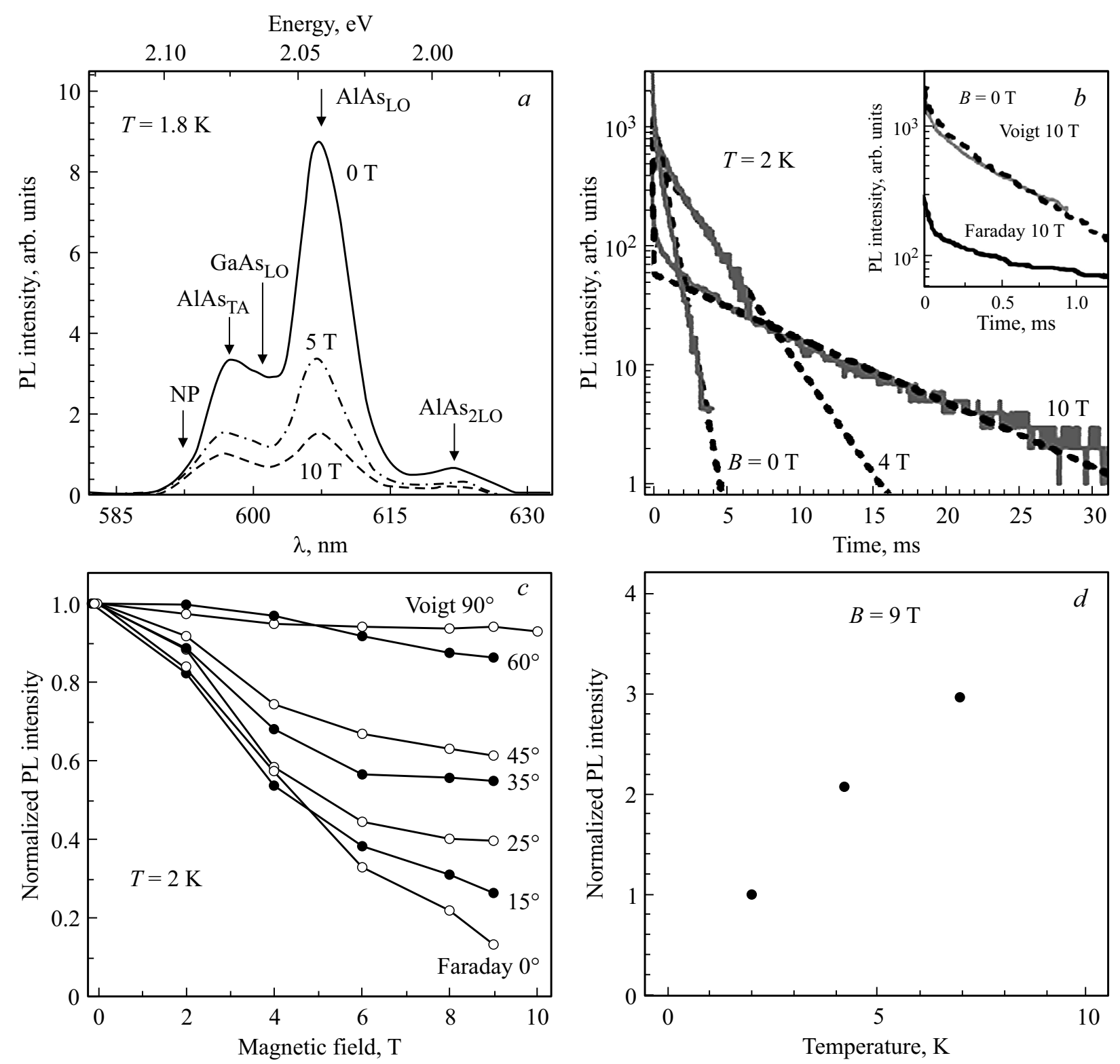

Pис. 4. (a) Спектры ФЛ GaAs/AlAs КЯ в продольных магнитных полях 0, 5 и 10 Т в геометрии Фарадея, стрелками показаны положения бесфононной полосы NP и ее фононных повторений [19]. (b) Динамика ФЛ GaAs/AlAs КЯ в полосе фононного повторения $\mathrm{AlAs}_{\mathrm{LO}}$ в продольных магнитных полях 0, 4 и $10 \mathrm{~T}$ в геометрии Фарадея. Штриховыми линиями показаны результаты расчетов по модели из работы [19]. На вставке динамика ФЛ GaAs/A1As КЯ в полях 0 Т (штриховая линия) и $10 \mathrm{~T}$ (черная линия — геометрия Фарадея, серая - Фохта). (c) Полевые зависимости интегральной интенсивности ФЛ GaAs/AlAs КЯ при различных углах между направлениями поля и волновым вектором излучаемых фотонов. (d) Температурная зависимость интегральной интенсивности ФЛ GaAs/AlAs КЯ в геометрии Фарадея в поле 9 T.

С подробной теорией, описывающей зависимости интенсивности и поляризации экситонной ФЛ и их динамики в ультратонкой квантовой яме GaAs/AlAs от температуры, напряженности и ориентации магнитного поля, можно познакомится в работах $[19,20,33]$. Здесь мы, не вдаваясь в детальное описание теоретической модели, приведем качественное объяснение наблюдаемых зависимостей. Тонкая структура состояний экситона в зависимости от напряженности продольного магнитного поля приведена на рис. $5 d$. Комбинация значений $g$ факторов электрона и дырки $\left(g_{e}=2\right.$ и $\left.g_{h h}=3.5 \pm 0.1\right)$ определяет последовательность состояний нижнее из которых, с проекцией момента -2 оптически неактивно. Время жизни экситона в этом состоянии $(8.5 \mathrm{~ms})$ заметно превышает время его излучательной рекомбинации в оптически активных состояниях $(0.34 \mathrm{~ms})$ [19]. При повышении напряженности продольного магнитного поля Зеемановское расщепление состояний приводит к тому, что энергетический зазор между нижним и возбужденными оптически активными состояниями начинает превышать тепловую энергию $k T$ (область II на рис. $5, d$ ). Энергетическая релаксация обуславливает конденсацию 

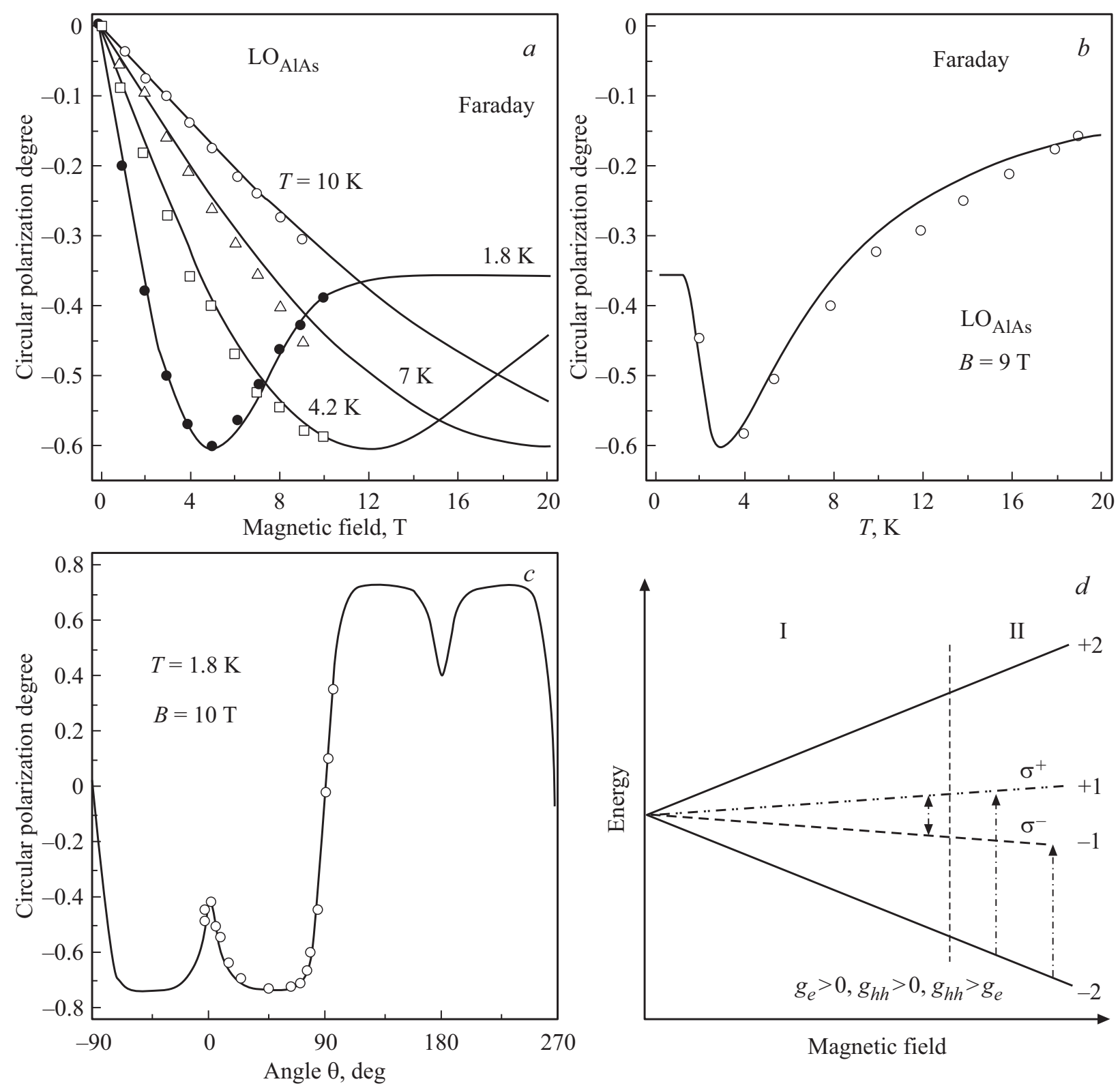

Рис. 5. Степень наведенной продольным магнитным полем циркулярной поляризации ФЛ GaAs/AlAs КЯ в полосе фононного повторения $\mathrm{AlAs}_{\mathrm{LO}}[20]:$ ( $a$ ) полевая зависимость при температурах, K: 1.8, 4.2, 7, 10; $(b)$ температурная зависимость в продольном поле $9 \mathrm{~T} ;(c)$ зависимость от ориентации магнитного поля $10 \mathrm{~T}$ при температуре $1.8 \mathrm{~K}$. $(d)$ Тонкая структура экситонных состояний в продольном магнитном поле. Цифрами, показаны проекции углового момента состояний. Вертикальными стрелками обозначены переходы из оптически неактивного состояния в оптически активные, необходимые для излучательной рекомбинации в сильных магнитных полях.

экситонов в долгоживущем нижнем состоянии, причем с ростом напряженности поля доля сконденсировавшихся в этом состоянии экситонов увеличивается. Поскольку рекомбинация экситона возможна только из оптически активного состояния, конденсация экситонов в оптически неактивном приводит к падению интенсивности и возрастанию времени жизни экситонов. В малых магнитных полях ФЛ, когда зеемановское расщепление между оптически активными и неактивными состояниями невелико по сравнению с тепловой энергией $k T$, степень циркулярной поляризации ФЛ возрастает из-за увеличения с ростом напряженности поля разности в тепловой заселенности оптически активных состояний экситона (проекция момента на ось роста структуры \pm 1$)$. В больших полях при конденсации экситонов в оптически неактивном состоянии заселение оптически активных состояний \pm 1 из состояния -2 определяется процессами с переворотом спина электрона и дырки (показаны вертикальными стрелками на рис. 5, b). Разность во временах спиновой релаксации электронов $(33 \pm 1 \mu \mathrm{s})$ и дырок $(3 \pm 0.5 \mu \mathrm{s})$ приводит к уменьшению разности в заселенности состояний \pm 1 и, как следствие, 
к уменьшению степени циркулярной поляризации ФЛ. При отклонении поля от геометрии Фарадея, смешивание оптически активных и неактивных состояний поперечной компонентой магнитного поля выравнивает скорости спиновой релаксации электронов и дырок, что приводит к повышению степени поляризации в сильных магнитных полях.

\section{4. Резонансное возбуждение непрямозонных экситонных состояний}

Слабое экситон-фотонное взаимодействие, обусловленное сохранением квазиимпульса, создает препятствия для применения резонансных методов возбуждений электронных состояний в непрямозонных гетероструктурах. Тем не менее, существуют подкласс непрямозонных гетеросистем особенности энергетического строения которых допускают резонансное оптическое возбуждение непрямых в пространстве квазиимпульсов экситонов. Одним из представителей таких систем являются квантовые точки, сформированные в гетеросистеме InAs/AlAs. Недавно было показано, что в ансамблях квантовых точек (In, Al)As/AlAs с дисперсией размеров могут сосуществовать точки, с нижним электронным состоянием, принадлежащим как Г, так и $X$ минимуму зоны проводимости [22]. В КТ большого размера нижний электронный уровень принадлежит $\Gamma$ минимуму зоны проводимости (см. рис. 1,c). С уменьшением размера КТ состояние электрона в Г минимуме зоны проводимости смещается значительно сильнее, чем состояние электрона в $X$ минимуме, как это видно на рис. 6, a. Это приводит к тому, что при некотором размере КТ, значение которого зависит от состава (In, Al)As, уровни электронов, принадлежащие $\Gamma$ и $X$ минимумам зоны проводимости, пересекаются (в точке обозначенной на рис. $6, a$ ), как $E_{\Gamma X}$ и состояние $X$ минимума становится нижним (см. рис. $1, d$ ), a состояние $\Gamma$ возбужденным электронным состоянием в КТ [12,34]. Модификация энергетического спектра при изменении размера КТ отчетливо проявляется в спектральной зависимости времени затухания экситонной ФЛ, измеренной в работе [34] при нерезонансном возбуждении и показанной на рис. $6, b$. В низкоэнергетической области спектра $(<1.6 \mathrm{eV})$, соответствующей рекомбинации прямозонных экситонов в „больших“ КТ, время затухания ФЛ составляет единицы наносекунд. В то же время в высокоэнергетической области спектра $(\hbar \omega>1.7 \mathrm{eV})$, соответствующей рекомбинации непрямозонных экситонов в ,маленьких“ КТ такое же затухание ФЛ длится десятки, и даже сотни микросекунд. Подансамбль КТ с близкими значениями энергий электронов в $\Gamma$ и $X$ минимумах зоны проводимости излучает в области энергий $1.6 \mathrm{eV} \ll \hbar \omega \ll 1.7 \mathrm{eV}$.

В этом разделе показано, что в КТ с совпадением энергий электронов, принадлежащим Г и $X$ минимумам зоны проводимости возможно резонансное, а для непрямозонной части ансамбля, квазирезонасное оптическое возбуждение электронных состояний принадлежащих $X$ долине зоны проводимости КТ.

А. Комбинационное рассеяние света с переворотом спина. Спектроскопия резонансного комбинационного рассеяния света с переворотом спина - когерентный резонансный оптический метод, широко использующийся для определения $g$ факторов квазичастиц в прямозонных полупроводниках и гетероструктурах [35]. Применение этого метода к анализу электронных и экситонных состояний в непрямозонных КТ становится возможным благодаря совпадению энергий электронов, принадлежащим $\Gamma$ и $X$ минимумам зоны проводимости. В идеальных объемных полупроводниках, волновые функции электронных состояний $\Gamma$ и $X$ долин не смешиваются друг с другом. Тем не менее, такое смешение может иметь место в низкоразмерных гетероструктурах изза нарушения трансляционной симметрии на границах раздела.

Спектры резонансного комбинационного рассеяния света с переворотом спина в ансамбле (In, Al)As/AlAs КТ измерялись в работе [34] в геометрии обратного рассеяния в скрещенных поляризациях при температуpe $1.8 \mathrm{~K}$ в магнитных полях 0-10 Т и с ориентацией магнитного поля относительно направления волнового вектора фотонов (совпадающего с осью симметрии КТ) от $\theta=0^{\circ}$ (геометрия Фарадея) до $\theta=90^{\circ}$ (геометрия Фохта) градусов. Спектры РКРС в магнитных полях 4 и 5 T показанные на рис. $6, c$ в наклонной геометрии $\theta=75^{\circ}$, содержат три линии, обусловленные переходами между расщепленными магнитными полем зеемановскими подуровнями, положение которых изменяется в зависимости от напряженности поля. Положения линий в спектре при изменении угла $\theta$ от $0^{\circ}$ до $90^{\circ}$ анализировались в работе [35] с учетом угловых зависимостей $g$-факторов $g(\theta)=\left[\left(g_{\|} \cos \theta\right)^{2}+\left(g_{\perp} \sin \theta\right)^{2}\right]^{1 / 2}$, где $g_{\|}$ и $g \perp$ соответственно компоненты тензора $g$ факторов вдоль и попрек оси симметрии КТ и соотношения $g_{e x}=g_{h h}-g_{e}$, связывающего $g$ фактора электрона $\left(g_{e}\right)$, тяжелой дырки $\left(g_{h h}\right)$ и экситона $\left(g_{e x}\right)$. Было показано, что линии $e, h h$, и $E x$ обусловлены переходами с переворотом спина: электрона в $X$ минимуме зоны проводимости, тяжелой дырки и непрямого в пространстве квазиимпульсов экситона, соответственно.

По рамановскому сдвигу линий были определены $g$ факторы квазичастиц. Для электрона $g_{e}=2.00 \pm 0.01$ изотропен, для тяжелой дырки продольная и поперечная компоненты $g$ фактора равны, соответственно, $g_{h h}^{\|} 2.42 \pm 0.05$ и $g \stackrel{\perp}{h h}=0.03 \pm 0.05$, а продольная и поперечная компоненты $g$ фактора экситона имеют разный знак $g_{e x}^{\|}=0.43 \pm 0.08$ и $g_{e x}^{\perp}=-1.95 \pm 0.08$. Угловые зависимости значений $g$-факторов приведены на рис. $6, d$. Для электрона в Г долине зоны проводимости значение $g$ фактора близко к нулю [36], поэтому, при использованных в работе [34] напряженностях магнитных полей, линия в спектрах РКРС, связанная с переворотом спина этого электрона маскируется излучением лазера. 

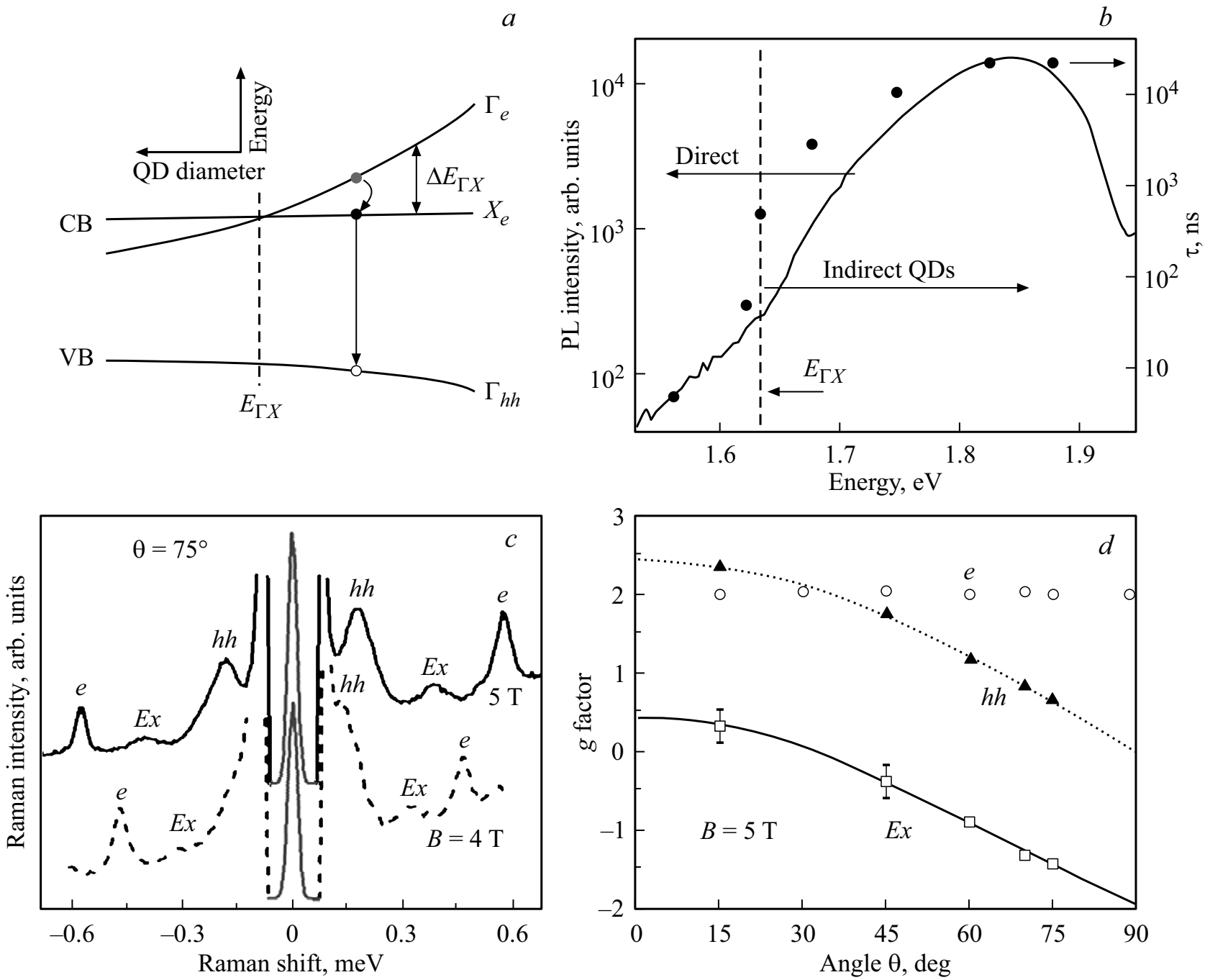

Рис. 6. (a) Зонная диаграмма (In, Al)As/AlAs KT различного размера. VB - положение потолка валентной зоны, CB дна зон проводимости. Разница в энергиях между электронными состояниями в $\Gamma$ и $X$ минимумах зоны проводимости обозначена как $\Delta E_{\Gamma X}$. Энергия $E_{\Gamma X}$, соответствует пересечению уровней электронов в Г и $X$ минимумах зоны проводимости при некотором характерном размере КТ [34]. (b) Спектр ФЛ ансамбля КТ при нерезонансном возбуждении $(\hbar \omega=3.49 \mathrm{eV})$ в нулевом магнитном поле при температуре $1.8 \mathrm{~K}$ (сплошная линия) и спектральная зависимость времени затухания экситонной ФЛ (заполненные кружки). Вертикальная пунктирная линия отмечает спектральное положение экситонной ФЛ в КТ с совпадающими энергиями состояний электронов в Г и $X$ долинах зоны проводимости. $(c)$ Спектры резонансного комбинационного рассеяния света с переворотом спина в ансамбле $(\mathrm{In}, \mathrm{Al}) \mathrm{As} / \mathrm{AlAs} \mathrm{KT}$ в магнитных полях 4 и 5 T при отклонении поля от геометрии Фарадея на угол $\theta=75^{\circ}$. Полосы $e$, $h h$ и $E x$ соответствуют переходам с переворотом спина электрона в $X$ долине зоны проводимости, дырки и непрямозонного экситона. $(d)$ Угловые зависимости значений $g$ факторов для электрона в $X$ долине зоны проводимости, дырки и непрямозонного экситона, определенные в работе [34] по Рамановскому сдвигу полос $e, h h$ и $E x$.

Из приведенных на рис. 7, $a$ резонансных зависимостей интенсивности рамановских переходов видно, что резонансное возбуждение электрона в $X$ минимуме зоны проводимости, происходит в узком диапазоне энергий (с максимумом в точке $E_{\Gamma X}$ ), соответствующем КТ с небольшой разницей в энергиях электронов, принадлежащим Г и $X$ минимумам зоны проводимости, обеспечивающей смешивание волновых функций этих состояний. В тоже время, спектральная зависимость интенсивности рамановских переходов с переворотом спина тяжелой дырки, описывается широким контуром с максимумом, сдвинутым примерно на $50 \mathrm{meV}$ в высокоэнергетическую область относительно энергии $E_{\Gamma X}$. Резонансной профиль переходов с переворотом спина тяжелой дырки, обусловлен, вовлечением в рамановский процесс реальных состояний прямых экситонов (состоящих из электрона и тяжелой дырки, локализованных в Г точке зоны Бриллюэна) в КТ. Для непрямозонных КТ время когерентности прямого экситона в этом состоянии ограничивается энергетической релаксацией электрона с переходом из $\Gamma$ в $X$ минимум зоны проводимости. Эффективность междолинной релаксации резко возрас- 

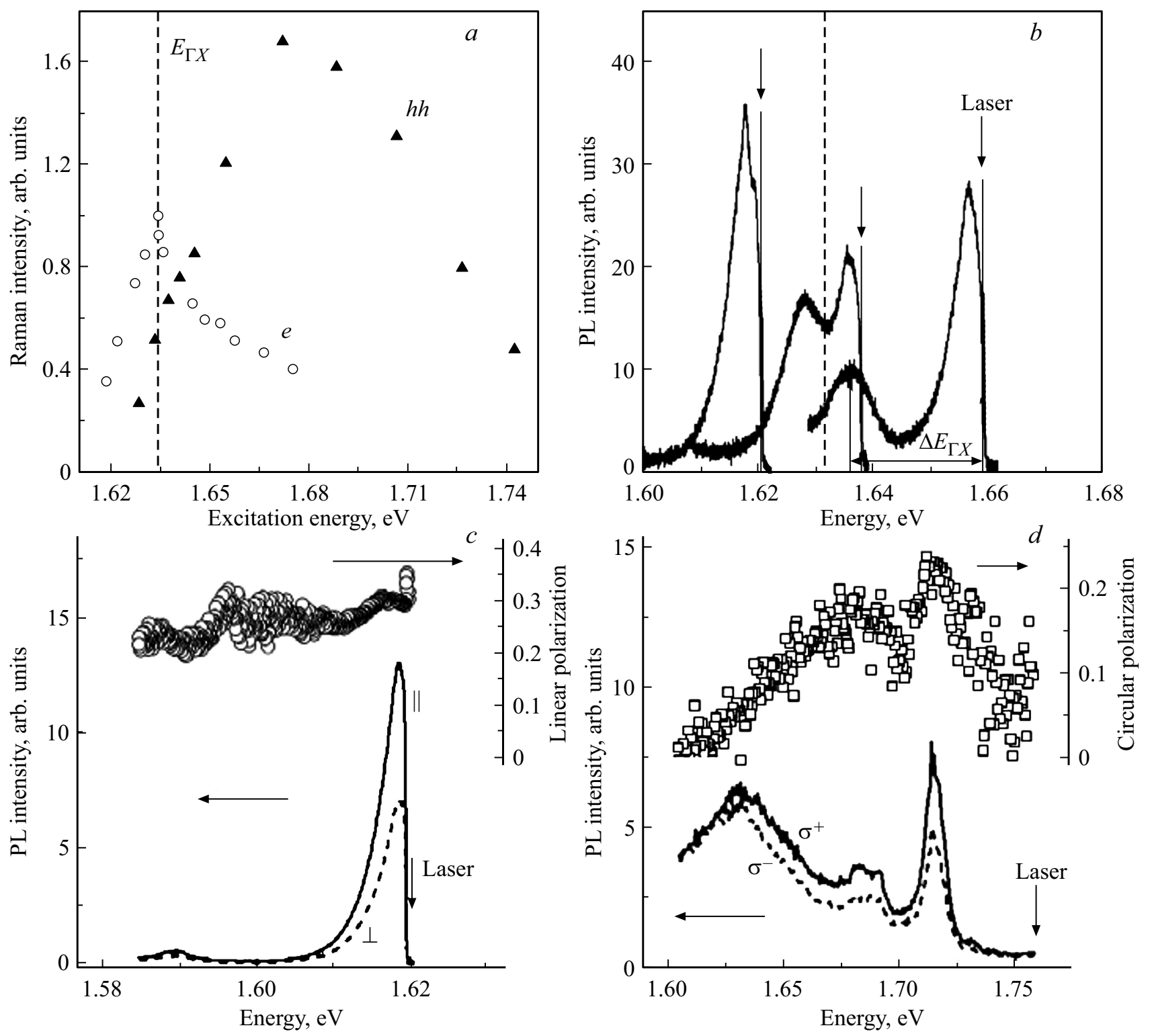

Рис. 7. (а) Резонансные профили для переходов с переворотом спина электрона $e$ и тяжелой дырки $h h$, в магнитном поле $5 \mathrm{~T}$, отклоненном на угол $\theta=75^{\circ}$ от геометрии Фарадея при температуре $1.8 \mathrm{~K} \mathrm{~K}$. Вертикальная пунктирная линия отмечает спектральное положение экситонной ФЛ в КТ с совпадающими энергиями состояний электронов в $Г$ и $X$ долинах зоны проводимости. $(b)$ Спектры ФЛ ансамбля (In, Al)As/AlAs KT, измеренные в режиме селективного возбуждения, при $T=5 \mathrm{~K}$. Энергии фотонов возбуждающего лазерного излучения обозначены вертикальными стрелками. Cпектры ФЛ (In, Al)As/AlAs и поляризация ФЛ при селективном лазерном возбуждении: (c) линейно поляризованным светом с энергий фотонов $1.62 \mathrm{eV}$, $(d)$ циркулярно поляризованным светом с энергий фотонов $1.76 \mathrm{eV}$ в прямозонной и непрямозонной части ансамбля КТ соответственно. Спектральные зависимости степени поляризации ФЛ показаны на правых осях рисунков.

тает при вовлечении в процесс релаксации оптических фононов [37]. Возрастание интенсивности полосы дырочного РКРС, при продвижении в высокоэнергетическую область спектра связано с ростом плотности КТ, а ее уменьшение начинается в КТ малого размера, когда разница в энергиях электронов, принадлежащим Г и $X$ минимумам зоны проводимости $\Delta E_{\Gamma X}$ начинает превышать энергию LO-оптического фонона в AlAs (48 meV) [32].

В. Оптическая ориентация непрямозонных экситонов. При селективном возбуждении ансамбля (In, Al)As/AlAs
КТ в приведенных на рис. $7, b$ спектрах ФЛ появляется серия полос с шириной много меньшей, чем ширина полосы при нерезонансном возбуждении, показанная на рис. 6, $b$. Полоса ФЛ на рис. 7,c в низкоэнергетической области спектра обусловлена резонансным возбуждением прямозонных КТ. Серия полос в спектре ФЛ при возбуждении в непрямозонной части ансамбля рис. 7, $d$ обусловлена тем, что фотоны с одной и той же энергией могут поглощаться в точках различного размера с разным энергетическим зазором $\Delta E_{\Gamma X}$ 
между возбужденным и основным состоянием. Каждая полоса соответствует рекомбинации экситонов в подансамбле КТ с близкой энергетической структурой. При резонансном возбуждении прямозонных КТ циркулярно поляризованным светом, ФЛ не поляризована. Однако при возбуждении этих КТ линейно поляризованным наблюдается линейная поляризация излучения (т. н. оптическое выстраивание, рис. 7,c), обусловленная хорошо известным эффектом смешивания экситонных состояний анизиторопным вкладом в обменное взаимодействие между электроном и дыркой в КТ, форма которых отклоняется от сферической. В непрямозонных КТ, отличающихся от прямозонных только размером, но не формой, напротив, при линейно поляризованном возбуждении оптическое выстраивание отсутствует, а при возбуждении циркулярно поляризованным светом, излучение циркулярно поляризовано (рис. 7,d). Оптическая ориентация в непрямозоных КТ связана с подавлением обменного взаимодействие между электроном и дыркой локализованных в разных точках зоны Бриллюэна. Степень поляризации ФЛ при квазирезонансном возбуждении определяется деполяризацией электрона в процессе энергетической релаксации при междолинном рассеянии, она зависит от величины энергетического зазора $\Delta E_{\Gamma X}$ в КТ и неоднородна по спектру.

\section{5. Заключение}

Таким образом, несмотря на ограничения, накладываемые в непрямозонных гетероструктурах законом сохранения квазиимпульса на один из фундаментальнейших параметров экситона - время рекомбинации, существует возможность управлять временами жизни экситона в широких пределах, от десятков наносекунд до сотен микросекунд. Увеличение времени жизни экситона в квантовых ямах и квантовых точках с таким энергетическим спектром возможно за счет изменения структуры гетерограницы при ее „диффузном“ размывании в процессе послеростового высокотемпературного отжига, уменьшающем смешивание волновых функций электронных состояний, принадлежащих различным минимумам зоны проводимости.

Длительность времен рекомбинации делает непрямозонные гетероструктуры удобными объектами для изучения спиновой динамики локализованных экситонов, для которых подавление основных механизмов, определяющих переворот спина свободно двигающихся электронных возбуждений, драматически замедляет времена спиновой релаксации.

В общем случае, слабость экситон-фотонного взаимодействия в непрямозонных гетероструктурах любого типа обуславливает метод создания неравновесной спиновой заселенности в этих объектах — одинаковое заполнение при нерезонансном неполяризованном оптическом возбуждении экситоных состояний, расщепленных в магнитном поле до величин, превышающих тепловую энергию $k T$. Процессы, спиновой релаксации, стремящиеся привести заселенности экситонных состояний в соответствие с равновесным (больцмановским) распределением индуцируют появление в таких системах наведенной магнитным полем циркулярной поляризации фотолюминесценции. Степень поляризации может контролироваться либо термодинамическими параметрами, т. е. отношением зеемановского расщепления к тепловой энергии, либо кинетическими параметрами, т.е. соотношениями между различными временами релаксации в системе, в зависимости от температуры и магнитного поля. Разработанный в работах [20,33] подход анализа наведенной магнитным полем циркулярной поляризации ФЛ может быть легко использован при исследовании спиновой динамики в любых полупроводниковых квантовых ямах и структурах с квантовыми точками с непрямой запрещенной зоной, как в реальном пространстве, так и в пространстве квазиимпульсов.

В частном случае непрямозонных гетеросистем, для которых имеет место определяемая параметрами формирующих квантовые точки полупроводников, особенность энергетического спектра - переход основного электронного уровня из прямозонного в непрямозонное состояние при уменьшение размера квантовой точки, можно создавать неравновесную спиновую заселенность непрямозонных экситонных состояний в режиме оптической ориентации при квазирезонансном возбуждении фотолюминесценции.

В этих же системах возможно формирование подансамбля КТ с близкими значениями энергий электронов в прямом и непрямом минимумах зоны проводимости с сильным смешиванием волновых функций этих электронных состояний. В таком подансамбле КТ возможно резонансное когерентное оптическое возбуждение состояний тяжелых дырок, электронов, локализованных в непрямых минимумах зоны проводимости, и непрямзонных экситонов. Когерентная оптическая инициализация и управление долгоживущими спиновыми состояниями электронов в боковых долинах зоны проводимости, для которых подавлено спин-орбитальное взаимодействие, делает такие КТ перспективными объектами для квантовых информационных технологий.

Автор выражает искреннюю благодарность коллегам по совместной работе по излучению непрямозонных гетероструктур А.И. Торопову, А.К. Бакарову, Д.В. Дмитриеву, А.К. Калагину, М.А. Путято, синтезировавших образцы, А.К. Гутаковскому, проводившему структурные измерения, Д.С. Абрамкину, А.В. Ненашеву, рассчитывающих энергетические спектры структур, J. Debus, D. Dunker, J. Rautert, A.M. Гилинскому за помощь при проведении измерений, В.Ф. Сапега, Д.Р. Яковлеву, М. Bayer, за плодотворные обсуждения полученных результатов, Л.С. Брагинскому, Е.Л. Ивченко, М.М. Глазову за теоретическую поддержку. 


\section{Список литературы}

[1] Optics of Semiconductors and Their Nanostructures / Ed. H. Kalt, M. Hetterich. Springer-Verlag, Berlin (2004).

[2] R. Cingolani, K. Ploog. Adv. Phys. 40, 535 (1991).

[3] F. Hatami, M. Grundmann, N.N. Ledentsov, F. Heinrichsdorff, R. Heitz, J. Böhrer, D. Bimberg, S.S. Ruvimov, P. Werner, V.M. Ustinov, P.S. Kop'ev, Zh.I. Alferov. Phys. Rev. B 57, 4635 (1998).

[4] T.S. Shamirzaev, A.M. Gilinsky, A.K. Kalagin, A.V. Nenashev, K.S. Zhuravlev. Phys. Rev. B 76, 155309 (2007).

[5] L.P. Fu, F.T. Bacalzo, G.D. Gilliland, R. Chen, K.K. Bajaj, J. Klem, D.J. Wolford. Phys. Rev. B 52, 2682 (1995).

[6] A.V. Khaetskii, Yu.V. Nazarov. Phys. Rev. B 61, 12639 (2000).

[7] A.V. Khaetskii, Yu.V. Nazarov. Phys. Rev. B 64, 125316 (2001).

[8] O.G. Schmidt, K. Eberl. Phys. Rev. B 61, 13721 (2000).

[9] D. Scalbert, J. Cernogora, C. Benoit 'a la Guillaume, M. Maaref, F.F. Charı, R. Planel. Solid State Commun. 70, 945 (1989).

[10] Т.С. Шамирзаев. ФТП 45, 97 (2011).

[11] M.-E. Pistol, C.E. Pryor. Phys. Rev. B 80, 035316 (2009).

[12] T.S. Shamirzaev, A.V. Nenashev, A.K. Gutakovskii, A.K. Kalagin, K.S. Zhuravlev, M. Larsson, P.O. Holtz. Phys. Rev. B 78, 085323 (2008).

[13] T.S. Shamirzaev, D.S. Abramkin, A.K. Gutakovskii, M.A. Putyato. Письма в ЖЭТФ 95, 601 (2012).

[14] Д.С. Абрамкин, К.М. Румынин, А.К. Бакаров, Д.А. Колотовкина, А.К. Гутаковский, Т.С. Шамирзаев. Письма в ЖЭТФ 103, 785 (2016).

[15] T.S. Shamirzaev, D.S. Abramkin, A.K. Gutakovskii, M.A. Putyato. Appl. Phys. Lett. 97, 023108 (2010).

[16] D.S. Abramkin, M.A. Putyato, S.A. Budennyy, A.K. Gutakovskii, B.R. Semyagin, V.V. Preobrazhenskii, O.F. Kolomys, V.V. Strelchuk, T.S. Shamirzaev. J. Appl. Phys. 112, 083713 (2012).

[17] Д.С. Абрамкин, М.А. Путято, А.К. Гутаковский, Б.Р. Семягин, В.В. Преображенский, Т.С. Шамирзаев. ФТП 46, 1571 (2012).

[18] C. Robert, C. Cornet, P. Turban, T. Nguyen Thanh, M.O. Nestoklon, J. Even, J.M. Jancu, M. Perrin, H. Folliot, T. Rohel, S. Tricot, A. Balocchi, D. Lagarde, X. Marie, N. Bertru, O. Durand, A. Le Corre. Phys. Rev. B 86, 205316 (2012).

[19] T.S. Shamirzaev, J. Debus, D.R. Yakovlev, M.M. Glazov, E.L. Ivchenko, M. Bayer. Phys. Rev. B 94, 045411 (2016).

[20] T.S. Shamirzaev, J. Rautert, D.R. Yakovlev, J. Debus, A.Yu. Gornov, M.M. Glazov, E.L. Ivchenko, M. Bayer. Phys. Rev. B 96, 035302 (2017).

[21] T.S. Shamirzaev, J. Debus, D.S. Abramkin, D. Dunker, D.R. Yakovlev, D.V. Dmitriev, A.K. Gutakovskii, L.S. Braginsky, K.S. Zhuravlev, M. Bayer. Phys. Rev. B 84, 155318 (2011).

[22] T.S. Shamirzaev, A.V. Nenashev, K.S. Zhuravlev. Appl. Phys.Lett. 92, 213101 (2008).

[23] P. Offermans, P.M. Koenraad, J.H. Wolter, K. Pierz, M. Roy, P.A. Maksym. Phys. Rev. B. 72, 165332 (2005).

[24] N. Liu, J. Tersoff, O. Baklenov, A.L. Holmes, Jr., C.K. Shih. Phys. Rev. Lett. 84, 334 (2000).

[25] E. Placidi, F. Arciprete, M. Fanfoni, F. Patella, E. Orsini, A. Balzarotti. J. Phys. Condens. Matter. 19, 225006 (2007).

[26] R. Panat, K.J. Hsia, D.G. Cahill. J. Appl. Phys. 97, 013521 (2005).
[27] Ch. Heyn, W. Hansen. J. Cryst. Growth. 251, 140 (2003).

[28] Е.Б. Александров, В.С. Запасский. ЖЭТФ 81, 132 (1981).

[29] D. Dunker, T.S. Shamirzaev, J. Debus, D.R. Yakovlev, K.S. Zhuravlev, M. Bayer. Appl. Phys. Lett. 101, 142108 (2012).

[30] M. Trif, P. Simon, D. Loss. Phys. Rev. Lett. 103, 106601 (2009).

[31] L.M. Woods, T.L. Reinecke, Y. Lyanda-Geller. Phys. Rev. B 66, 161318 (2002).

[32] Physics of Group IV Elements and III-V Compounds / Ed. O. Madelung, M. Schulz, H. Weiss, Landolt-Börnstein Numerical Data and Relationships. New Ser. Group III. V. 17, pt. A Springer, Berlin, (1982).

[33] Е.Л. Ивченко. ФТТ 60, 7, 1503 (2018).

[34] J. Debus, T.S. Shamirzaev, D. Dunker, V.F. Sapega, E.L. Ivchenko, D.R. Yakovlev, A.I. Toropov, M. Bayer. Phys. Rev. B 90, 125431 (2014).

[35] V.F. Sapega, M. Cardona, K. Ploog, E.L. Ivchenko, D.N. Mirlin. Phys. Rev. B 45, 4320 (1992).

[36] I.A. Yugova, A. Greilich, D.R. Yakovlev, A.A. Kiselev, M. Bayer, V.V. Petrov, Yu.K. Dolgikh, D. Reuter, A.D. Wieck. Phys. Rev. B 75, 245302 (2007).

[37] И.Я. Карлик, Д.Н. Мирлин, В.Ф. Сапега. ФТП 21, 1030 (1987).

Редактор Т.Н. Василевская 